\title{
P\&D DE INTERESSE PÚBLICO? OBSERVAÇÕES A PARTIR DO ESTUDO DA EMBRAPA E DA PETROBRAS
}

\author{
Marcos Paulo Fuck ${ }^{1}$ \\ Cassio Garcia Ribeiro ${ }^{2}$ \\ Maria Beatriz Machado Bonacelli ${ }^{3}$ \\ André Tosi Furtado ${ }^{4}$
}

\begin{abstract}
Resumo: O setor público desempenha diversas funções na economia. Nas últimas décadas, percebe-se um intenso debate acerca das atividades que deveriam ser executadas, ou mesmo financiadas, pelo setor público. Muito se fala sobre uma possível divisão de trabalho dentro do processo produtivo, com algumas atividades sendo em tese mais interessantes à iniciativa privada e outras ao setor público. $\mathrm{O}$ objetivo do artigo é discutir criticamente o papel do setor público nas atividades de ciência e tecnologia a partir de dois casos relevantes: o da Embrapa e da Petrobras. Trata-se de duas empresas brasileiras de liderança mundial nas áreas de agropecuária e de petróleo, respectivamente. Ambas são empresas de destacada importância para a economia nacional e vinculadas ao setor público, desenvolvem pesquisa básica e aplicada e atuam em mercados em que a iniciativa privada também se faz presente.
\end{abstract}

Palavras chaves: Inovação Tecnológica; Intervenção Estratégica; Relações PúblicoPrivado.

\begin{abstract}
The public sector plays multiple roles in the economy. In the recent decades, has been noted an intense debate concerning what activities should be implemented, or even financed, by the public sector. Much has been talked about a possible division of labor in the productive process with some activities being, in thesis, more interesting to private initiative and other to the public sector. The goal of this paper is critically discuss the role of the public sector in science and technologies activities from two relevant cases: Embrapa and Petrobras. These are two Brazilian companies of global leadership in the areas of agriculture and oil, respectively. Both companies are of importance highlighted for the national economy and linked to the public sector, develop basic and applicable research and operate in markets that the private initiative also is present.
\end{abstract}

Key words: Technological Innovation; Strategic Intervention; Public-Private Relationships

\footnotetext{
${ }^{1}$ DPCT/IG/Unicamp, fuck@ige.unicamp.br

2 DPCT/IG/Unicamp, cassio@ige.unicamp.br.

${ }^{3}$ DPCT/IG/Unicamp, bia@ige.unicamp.br.

${ }^{4}$ DPCT/IG/Unicamp, furtado@ige.unicamp.br.
} 


\section{INTRODUÇÃO}

Definir a priori quais atividades devem ser realizadas pelo setor público ou privado tendo como ponto de partida a maior ou menor proximidade com $\mathrm{o}$ mercado e a possibilidade de retornos financeiros dos investimentos realizados, entre outros, tem cada vez menos respaldo conceitual e um entendimento que não contempla a complexidade do processo de geração e de desenvolvimento do conhecimento e da inovação, da relação entre os atores envolvidos nesse processo e da lógica da apropriação dos resultados das atividades de ciência e tecnologia (C\&T). Tal discussão, na verdade, não diz respeito apenas às atividades de pesquisa científica e tecnológica, mas à praticamente todas as atividades econômicas. De uma forma geral, alguns autores consideram que o principal fator a ser considerado nessa divisão de trabalho, inclusive em P\&D, seria relacionado à apropriabilidade dos investimentos realizados. Ou seja, as atividades que geram produtos mais facilmente apropriáveis seriam em princípio mais atrativas à iniciativa privada, enquanto as atividades de menor ou de mais incerta apropriação seriam de responsabilidade do setor público. Dada a dificuldade em se tratar de temas em nível tão abstrato, o objetivo do artigo é discutir a questão da divisão do trabalho nas atividades de pesquisa científica e tecnológica a partir de dois casos concretos: o da Empresa Brasileira de Pesquisa Agropecuária (Embrapa) e da Petróleo Brasileiro S/A (Petrobras). Tratam-se de duas empresas brasileiras de liderança mundial nas áreas de agropecuária e de petróleo, respectivamente. A Embrapa é considerada a principal Instituição de Pesquisa em nível mundial que desenvolve trabalhos voltados à pesquisa em agricultura tropical. Por sua vez, a Petrobras se destaca também em nível mundial, na exploração de petróleo em águas profundas. Ambas são empresas vinculadas ao setor público; contudo, a
Petrobras, na condição de sociedade de economia mista, sofre influência dos interesses dos acionistas privados. Em que pese essa diferença entre as duas entidades ora analisadas, observa-se uma característica similar entre elas que é o engajamento em atividades de pesquisa básica e aplicada, bem como sua presença em mercados em que a iniciativa privada também se faz presente. A idéia do artigo é justamente destacar a importância dessas atividades como forma de ampliar o poder de intervenção pública em áreas de grande interesse nacional.

No caso da Embrapa, a instituição desenvolve pesquisa para culturas voltadas a pequenos produtores, que por conta disso são pouco atrativas à iniciativa privada. Desenvolve também pesquisas voltadas às culturas que envolvem maior movimentação financeira, onde as empresas privadas, sobretudo multinacionais, também estão presentes. Neste segundo caso, a forma de intervenção da Embrapa amplia a concorrência no mercado de sementes, por exemplo, e explora as alternativas tecnológicas visando o atendimento de um público mais amplo. No caso da Petrobras, destacam-se os esforços tecnológicos empreendido pelo Cenpes o centro de pesquisa desta empresa, sobretudo no que diz respeito às atividades de exploração e produção de petróleo no offshore. Tais esforços permitiram o alcance da auto-suficiência do Brasil em petróleo. Cabe aqui destacar também a transferência de tecnologias desenvolvidas pela Petrobras à indústria de fornecedores, fato decisivo para a consolidação dessa indústria.

O trabalho é baseado em ampla revisão bibliográfica sobre os temas em questão. Na parte teórica, destacam-se as contribuições de inspiração neoschumpeteriana, da sociologia da inovação, entre outras, para debater os aspectos conceituais referentes à chamada $\mathrm{P} \& \mathrm{D}$ de interesse público. Os estudos de caso se baseiam nos diversos estudos já realizados sobre as Instituições em questão e também em entrevistas e estudos realizados pelos próprios autores. 
Os resultados obtidos salientam a importância das duas instituições em suas respectivas áreas de atuação e apontam elementos importantes para o debate sobre o papel do setor público nas atividades de C\&T. Mais do que realizar trabalhos em áreas pouco lucrativas ou desenvolver somente pesquisa básica, essas instituições vêm ocupando importantes espaços estratégicos, contribuindo com o crescimento do país e, acima de tudo, ampliando os benefícios sociais e econômicos decorrentes das tecnologias desenvolvidas. Em meio às diversas mudanças institucionais por que passam as duas instituições brasileiras, entende-se que os resultados alcançados por elas devem ser ressaltados e que as mudanças em curso devem ser de modo a ampliar ainda mais a capacitação de tais instituições para atuar em mercados cada vez mais competitivos.

Além desta introdução e das conclusões, o artigo possui outros quatro itens: no primeiro apresenta-se uma breve discussão teórica sobre as atividades de pesquisa realizadas pelo setor público e privado; o segundo capítulo destaca o conceito de pesquisa e desenvolvimento (P\&D) de interesse público; no terceiro apresenta-se a forma de atuação da Embrapa na pesquisa e no mercado de sementes no Brasil, destacando suas articulações com o setor privado; no quarto é analisado o caso da Petrobras, destacando a P\&D realizada por seu centro de pesquisa e o papel de dois mecanismos criados pelo governo brasileiro pós-quebra do monopólio da Petrobras, quais sejam, o CT-Petro e a cláusula de investimento em $\mathrm{P} \& \mathrm{D}$, no fomento às atividades científicas e tecnológicas da indústria do petróleo brasileira. Nas conclusões destacam-se alguns elementos sobre a importância do papel das duas entidades governamentais estudadas em suas respectivas áreas de atuação como forma de ocupar importantes espaços estratégicos e permitir uma apropriação social menos desigual dos resultados alcançados.

\section{A DIFICULDADE EM SE DEFINIR O QUE CABE AO SETOR PÚBLICO E AO PRIVADO NO DESENVOLVIMENTO DA PESQUISA}

A abordagem mais convencional do pensamento econômico considera que as políticas públicas compensariam as chamadas falhas de mercado, situações nas quais os mercados não agem eficientemente, com o sistema de preços não sinalizando aos agentes a quantidade ótima de bens e serviços a ser produzida. Os dois principais exemplos de falhas de mercado são as externalidades e os bens públicos. Contudo, além desses dois casos, há uma outra falha de mercado com forte presença nos países periféricos, qual seja, a existência de mercados incompletos. Tal falha pode ocorrer porque mesmo que se trate de atividades típicas de mercado, nem sempre o setor privado está disposto a assumir os riscos. No que toca aos países em desenvolvimento há muitos casos em que é necessária uma coordenação dos mercados em alta escala, de modo que se justifica a intervenção governamental mediante processos de planejamento. Um exemplo claro disso é quando o objetivo de uma industrialização rápida de um país periférico pode demandar uma ordenação de setores prioritários para a instalação da indústria (Giambiagi \& Além, 1999). O setor do petróleo e gás natural no Brasil, sobretudo na época da formação da Petrobras, apresenta características que o encaixam nessa modalidade de falha de mercado, qual seja, os mercados incompletos. Os grandes investimentos necessários para a criação e consolidação do setor e o longo prazo para o retorno do investimento foram fatores determinantes para a forte presença do Estado na formação desse setor no Brasil.

Uma externalidade é o impacto das ações de um agente econômico sobre o bem-estar dos outros que não participam da ação. $\mathrm{Na}$ presença de externalidades, o interesse da sociedade em relação a um resultado de mercado 
vai além do bem-estar de compradores e vendedores do mercado; inclui também o bem-estar dos demais agentes afetados (Mankiw, 1999). Em relação aos atributos dos bens produzidos na economia, o viés teórico predominante considera duas dimensões fundamentais: a exclusividade e a rivalidade. A primeira refere-se à propriedade de um bem por meio da qual se pode impedir uma pessoa de usá-lo. Já a rivalidade refere-se à propriedade de um bem por meio da qual sua utilização por uma pessoa impede a outra de utilizá-lo. Ou seja, um bem é "excluível" se é possível excluir outros indivíduos do uso; ele é rival se o seu uso por um indivíduo evita outros de usá-lo.

Os bens públicos são igualmente disponíveis para todos e não podem ser apropriados por meio dos mecanismos de mercado, sendo impossível a utilização exclusiva de um bem por um indivíduo. Devido a tais características, a abordagem convencional aponta para a existência do "problema dos caronas", ou seja, como as pessoas não pagam pelo uso dos bens públicos, elas têm um incentivo a "pegar carona" quando o bem é fornecido privadamente. Por isso, o desenvolvimento de tais produtos ficaria a cargo de instituições "não voltadas ao lucro". No caso da pesquisa científica, se ela fosse inteiramente conduzida pelo setor privado, haveria um forte viés na alocação dos recursos, deixando muitas atividades (as de menor interesse financeiro) descobertas.

Callon (1994) propõe uma discussão mais profunda sobre os argumentos a respeito da definição de ciência como bem público. Além das duas dimensões discutidas acima (rivalidade e exclusividade), o autor apresenta mais duas características referentes ao conhecimento científico: a primeira, o conhecimento científico é um bem durável, ou seja, não é destruído ou alterado pelo seu uso (pelo contrário, quanto mais o conhecimento científico é utilizado, melhor ele se torna); a segunda, a produção de conhecimento é incerta, sendo impossível, em casos extremos, predizer seus resultados ou sua utilidade,

ENGEVISTA, v. 9, n. 2, p. 85-99, dezembro 2007 ou seja, possui um caráter estocástico, ao qual se associa elevada incerteza e alto risco.

$\mathrm{O}$ autor também considera que não há diferença, a priori, entre pesquisa pública e privada. $\mathrm{O}$ caráter privado ou público da ciência depende de uma série de investimentos em instituições e recursos humanos e da relação entre conhecimento e tecnologia. $\mathrm{O}$ autor ressalta que as tecnologias geralmente possuem retornos crescentes, graças ao aprendizado e às externalidades, vantagens adquiridas que reforçam a trajetória inicial e criam irreversibilidades. Além disso, a necessidade de aproveitar economias de escala em P\&D, dividir riscos e incertezas e explorar a complementaridade de ativos leva à formação de múltiplas formas de cooperação, configurando redes para desenvolver e explorar conhecimento.

Ainda segundo Callon (1994), a relação entre retornos crescentes e cooperação tem duas conseqüências: a primeira, ciência e tecnologia são endógenas ao sistema econômico; a segunda, as trajetórias decorrentes passam a ser construídas por "coletivos" formados por firmas, laboratórios de universidades e usuários, formando o que o autor chama de redes tecnoeconômicas flexíveis. Nelas, o público e o privado se complementam, redefinindo-se então o conceito de conhecimento como bem público (ou, mais especificamente, pesquisa pública) e tornando a ciência uma fonte de diversidade e flexibilidade. Assim, o apoio público à produção científica se justifica por permitir um grau necessário de variedade e de flexibilidade - conservando um nível de diversidade que permite deixar em aberto possibilidades de pesquisa - e não devido às características intrínsecas da ciência como bem público.

$\mathrm{O}$ entendimento de que o processo inovativo é afetado por variáveis que vão muito além da origem das instituições que participam do processo (sejam elas públicas ou privadas) e da importância estratégica dos investimentos em 
pesquisa (básicas ou aplicadas) como fonte de novas possibilidades de desenvolvimento científico (com impactos econômicos e sociais) avança conceitualmente $o$ debate sobre as interações entre os setores público e privado nas atividades de $P \& D$ e supera as insuficiências das visões mais convencionais sobre o assunto. Ajuda também no entendimento do espaço estratégico que pode ser ocupado pelo setor público no desenvolvimento $\mathrm{e}$ execução de várias atividades, inclusive de C\&T.

Reforçando os argumentos de $\mathrm{M}$. Callon, para Salles-Filho \& Kageyama (1998), a constatação de que firmas privadas investem em pesquisa básica e que instituições públicas financiam $o$ desenvolvimento de bens apropriáveis torna inapropriado o uso do conceito mais comum de bem público. Nem mesmo o conhecimento científico fundamental está isento de um certo grau de apropriabilidade e de presença de aprendizado, sendo artificial a divisão entre pesquisa básica e pesquisa aplicada e sua atribuição, respectivamente, ao setor público e ao setor privado. Essa divisão não apenas deixa de fazer sentido para justificar uma certa divisão de tarefas entre os setores público e privado, como também perde poder para explicar a realidade da organização contemporânea das atividades de P\&D.

\section{P\&D DE INTERESSE PÚBLICO: UMA TENTATIVA DE AVANÇO DAS CONCEPÇÕES}

Blumstein et al. (1999) definem P\&D de interesse público como sendo a atividade de P\&D que não é adequadamente concebida e financiada pelo mercado competitivo, uma vez que alguns ou todos os benefícios resultantes são amplamente difundidos e não podem ser capturados exclusivamente pelas empresas que a realizaram a ponto de justificar seu investimento.

Gomes (2003) expande a definição feita pelos autores, definindo $\mathrm{P} \& \mathrm{D}$ de interesse público como "aquelas atividades alinhadas com metas de desenvolvimento e cujos benefícios são importantes para o bem-estar social $e$ econômico e que não são adequadamente concebidas e financiadas pelo mercado competitivo, uma vez que alguns ou todos os benefícios resultantes são amplamente distribuídos e não podem ser apropriados individualmente (critério de exclusividade) pelas empresas a ponto de justificar seu investimento" (pg. 23). O autor ressalta que é de interesse do Poder Público garantir e estimular a realização deste tipo de atividade.

Referindo-se ao setor petróleo e gás natural, Santos (2003) conceitua P\&D de interesse público como sendo as atividades dirigidas à pesquisa e ao desenvolvimento, visando atender aos interesses públicos identificados a partir da Lei do Petróleo, cujos benefícios advindos desse tipo de atividade são importantes para o bem-estar social e econômico. Essa dimensão da $\mathrm{P} \& D$ de interesse público vai ser mais explorada no capítulo que trata da operadora nacional, mas vale destacar aqui que o grau de apropriabilidade da P\&D realizada por essa companhia é significativo, o que fica evidente a partir da quantidade de patentes detidas pela empresa. Isso significa que parte da $\mathrm{P} \& \mathrm{D}$ realizada pela Petrobras, seja com recursos próprios, seja com recursos oriundos dos mecanismos governamentais criados pós-quebra do monopólio, além de gerar benefícios sócio-econômicos ao país, também apresentam repercussão positiva para a empresa.

Além do "efeito transbordamento" (spillover) decorrente das atividades de pesquisa, a literatura destaca a ocorrência do chamado "efeito crowding out". A literatura que aborda tal questão geralmente critica a intervenção estatal na economia, pois, para autores à ela ligados, existe uma preocupação de que a P\&D realizada pela iniciativa privada possa ser "deslocada" pela $P \& D$ realizada pelo setor público e o uso do dinheiro público, gasto na realização da pesquisa, pode ser menos proveitoso para $o$ 
progresso técnico do que o investimento realizado pela iniciativa privada, que foi inibido (David \& Hall, 2000).

Assim, conforme explicam Bonacelli, Salles-Filho \& Silveira (2002), o efeito crowding out se refere ao afastamento/deslocamento da pesquisa privada causado pelos investimentos públicos em pesquisa. $\mathrm{O}$ suposto resultado desse efeito é que o gasto em pesquisa pública tem um efeito de substituição superior ao de complementariedade do gasto privado. Ou seja, a substituição surge quando há duplicação dos esforços de pesquisa, o que levaria ao sub-investimento privado, o efeito crowding out, que está diretamente relacionado à busca de eficiência na definição do mix de gastos do governo nas diferentes atividades de pesquisa e inovação. Já a complementariedade seria principalmente causada pelos efeitos de transbordamento e, principalmente, pela capacidade do investimento público orientar os caminhos da pesquisa para o futuro.

Seguindo a sugestão de Bonacelli, Salles-Filho \& Silveira (2002), entendese que melhor do que iniciar a análise a partir de uma suposta contraposição entre o setor público e privado na organização das atividades de pesquisa, é buscar o entendimento das dinâmicas técnicoconcorrenciais dos setores em estudo. Isso porque, por essa ótica, é possível identificar as principais características que justificam o papel dos atores tanto no que respeita a produção, como no que respeita o desenvolvimento das pesquisas, assim como o próprio arranjo entre os atores. Ou seja, entende-se como de fato se organiza esse sistema de inovação. Uma vez entendida a dinâmica dos segmentos em questão, percebe-se que pode ocorrer um efeito distinto ao crowding out uma vez que, como apontado por Fuck (2005), no caso da pesquisa referente às sementes de soja e milho há mais complementaridade do que substituição entre as ações da Embrapa e da iniciativa privada. Além disso, sobretudo no caso da soja, o Brasil tem uma forte tradição de pesquisa pública, $o$ que não pode ser negligenciado ao se analisar o mercado de sementes.

Conforme Fuck (2005), se se aplicasse essa idéia de P\&D de interesse público para o caso da atuação da Embrapa no mercado nacional agropecuário, a instituição deveria ficar mais focada em mercados menos atrativos à iniciativa privada e reformular sua forma de atuação nos mercados que possuem maior expectativa de rentabilidade. Porém, ao participar de forma ativa no mercado nacional de sementes de soja e milho híbrido (que foram estudados pelo autor), a Embrapa amplia a concorrência nesses mercados. Ou seja, mesmo com a forte participação da iniciativa privada nesses mercados, cabe à Embrapa desenvolver pesquisa como forma de garantir a competitividade das empresas sementeiras de menor porte, evitando que esses mercados sejam definitivamente dominados por grandes corporações, notadamente multinacionais (essa discussão é retomada no item referente à Embrapa). Ademais, a intervenção pública possibilita a criação de uma mediação entre empresas sementeiras e produtores rurais nacionais, permitindo que características específicas desses últimos passem a ser levadas em conta.

Com o avanço nas pesquisas em biotecnologia, esta necessidade é ainda mais evidente. Isso porque esta nova tecnologia está concentrada em poucos produtos e são amplas as possibilidades a serem exploradas com a utilização desse novo conhecimento. Então, mais do que corrigir falhas de mercado ou mesmo ampliar a concorrência em mercados pouco competitivos, a realização de pesquisas em biotecnologia por parte de instituições públicas de pesquisa permite o desenvolvimento e a absorção de novos conhecimentos, o acompanhamento da evolução da fronteira tecnológica e da organização dos mercados e setores econômicos, assim como a ampliação da variedade e da flexibilidade da pesquisa, independente do grau de concorrência e da estrutura dos mercados em questão. Isso é realizar P\&D de interesse público. 
Assim, entende-se que a Embrapa executa $\mathrm{P} \& \mathrm{D}$ de interesse público tanto nos segmentos em que a iniciativa privada não tem interesse em investir (nos mercados de baixa rentabilidade), como naqueles em que a participação da iniciativa privada é significativa. Isso significa dizer que as IPPs podem realizar P\&D de interesse público em mercados com diferentes níveis de interesse da iniciativa privada, uma vez que, na grande maioria dos casos, existe um espaço estratégico a ser ocupado pela pesquisa pública. Os resultados gerados dentro de uma perspectiva estratégica podem conformar trajetórias complementares entre pesquisa pública e privada.

O caso da Petrobras é um pouco distinto do da Embrapa. A história da Petrobras praticamente se confunde com a da indústria do petróleo no Brasil. A criação dessa companhia ocorreu, não apenas por motivações nacionalistas, mas também a partir de duas constatações: $1^{\text {a }}$ ) o setor petrolífero seria de fundamental importância para a industrialização do país e; $2^{\mathrm{a}}$ ) os investimentos privados no setor não eram condizentes com as necessidades da sociedade, ou seja, tratava-se de um mercado incompleto. Logo, os investimentos em P\&D que sempre caracterizaram sua atuação, mais do que ocupar um espaço deixado pelo mercado, estão (e sempre estiveram) relacionados com a própria sobrevivência e o dinamismo da empresa. Nesse contexto, os impactos sócio-econômicos acabam sendo um subproduto da P\&D realizada pela Petrobras, cujo foco, na realidade, são os resultados econômicos e tecnológicos que essa atividade proporciona à empresa. Ou seja, pode-se dizer que a P\&D levada a cabo pela operadora nacional se apresenta como uma externalidade benéfica para a sociedade brasileira.

Nos próximos dois capítulos deste artigo passa-se a discutir a forma de atuação da Embrapa e da Petrobras e o posicionamento estratégico que elas adotam junto aos demais atores envolvidos no cenário inovativo.

ENGEVISTA, v. 9, n. 2, p. 85-99, dezembro 2007

\section{A FORMA DE ATUAÇÃO DA EMBRAPA NA PESQUISA E NO MERCADO DE SEMENTES NO BRASIL}

A Embrapa é uma empresa pública de direito privado. Ela é vinculada ao Ministério da Agricultura, Pecuária e Abastecimento, tendo sido criada em 1973, substituindo o DNPEA (Departamento Nacional de Pesquisa Agropecuária). Ela é a maior e principal instituição de pesquisa agropecuária do país e, na esfera internacional, destaca-se como o principal centro de tecnologia agropecuária tropical. Sua missão é viabilizar soluções para o desenvolvimento sustentável do espaço rural, com foco no agronegócio, por meio da geração, adaptação e transferência de conhecimentos e tecnologias, em benefício dos diversos segmentos da sociedade brasileira. Atualmente, a Embrapa atua por intermédio de 38 Unidades de Pesquisa, 3 Serviços e 13 Unidades Administrativas, estando presente em quase todos os Estados da Federação, nas mais diferentes condições ecológicas.

A Embrapa executa suas funções públicas de diversas maneiras. SallesFilho et al. (2000) consideram que as IPPs podem executar algumas funções públicas, como por exemplo: geração de conhecimento estratégico; formulação de políticas públicas; execução de políticas públicas; geração de oportunidades de desenvolvimento; e arbitragem. Referindo-se ao caso da Embrapa, os autores consideram que apesar de historicamente a Instituição não ter tido na geração de conhecimento estratégico um objeto prioritário de atuação, existe uma tendência atual na busca de capacitação adquirida para a solução de problemas específicos. A formulação de políticas públicas é fortemente executada pela Embrapa garantindo-lhe legitimidade e sustentabilidade institucional ao longo de sua existência. A execução de políticas públicas faz parte da missão histórica da Instituição, sendo, portanto, sua grande fonte de 
sustentabilidade institucional. A Instituição também apóia projetos estratégicos do governo federal, tais como: Produção de Biodiesel e de Biocombustivéis, Defesa Agropecuária, Mecanismo de Desenvolvimento Limpo, Combate às Queimadas e ao Desmatamento da Amazônia, Arranjos Produtivos Locais, Zoneamento Ecológico-econômico, Zoneamento Agroclimático, Segurança Alimentar e Inclusão Social (Campanhola, 2004). Já na função arbitragem tem exemplos na atuação de vários centros da Instituição (emissão de parecer técnico, laudos técnicos sobre qualidade dos produtos, controle do ingresso de recursos genéticos etc.).

A geração de oportunidades de desenvolvimento deriva da capacidade de que as soluções tecnológicas se insiram num contexto maior do que o da Instituição. Segundo o Balanço Social 2005, o lucro social da Embrapa foi de R\$ 12.955.643.778,07. Este número, dividido pela Receita Operacional Líquida, indica que, em 2005, para cada $\mathrm{R} \$ 1,00$ aplicado na Embrapa, R\$ 14,00 retornaram para a sociedade brasileira. Esses valores levam em conta apenas a soma dos ganhos relativos à adoção de uma amostra de 86 tecnologias e 170 cultivares. Conforme destaca a instituição, esses números representam mais empregos gerados, mais desenvolvimento para o sistema produtivo, mais alimentos, maior preservação ambiental, entre outros fatores $^{5}$.

Além das cinco funções públicas citadas, Fuck (2005) considera que as IPPs também executam uma função pública ao conhecer as especificidades dos mercados em que atuam para antecipar suas ações no cenário inovativo e para direcionarem adequadamente suas próprias atividades de pesquisa científica e tecnológica. Essa capacidade de monitoramento dos mercados estaria relacionada a dois aspectos principais:

\footnotetext{
${ }^{5}$ Informação obtida em

www.sct.embrapa.br/balanco2005/site.html, acesso em 25/maio/2007.
}

ENGEVISTA, v. 9, n. 2, p. 85-99, dezembro 2007 conhecimento do mercado para o desenvolvimento de novos produtos e processos; e conhecimento do mercado para melhor definir as estratégias de relacionamento com demais atores.

Referindo-se à forma como a Embrapa executa essa função pública, Fuck (2005) destaca, entre outros novos produtos, as pesquisas em biotecnologia realizadas pela Instituição para o desenvolvimento de variedades transgênicas. Destaca também a forma de atuação da Embrapa no mercado de sementes de soja e milho, as duas principais commodities produzidas pelo Brasil $^{6}$. Os contratos com fundações de produtores de sementes e com as próprias empresas multinacionais são exemplos de como a Instituição vem se posicionando na organização dos mercados de sementes. No mercado de sementes de soja, a Embrapa adota estratégias tecnológicas ofensivas, tanto no melhoramento tradicional como na geração de sementes transgênicas. Por outro lado, conforme Salles-Filho et al. (2000), a estratégia da Embrapa de desenvolvimento de matrizes genéticas de aves de corte convencionais mostrouse menos favorável. A tentativa de entrada em um oligopólio mundial fugiu às capacitações (e mesmo à missão) da Instituição. Melhor seria (como vem sendo feito) investir no desenvolvimento de matrizes genéticas para mercados alternativos, como são os de aves caipiras, voltados à pequena produção. " $A$ decisão de ingressar ou não no desenvolvimento de genética de aves para a produção industrial passa necessariamente por uma avaliação de mercado, dos mecanismos de concorrência e de apropriabilidade e da dinâmica de inovação tecnológica presente" (Salles-Filho et al., 2000:63).

A ampliação dessa capacidade de monitoramento e de sua rede de

\footnotetext{
${ }^{6}$ A previsão da Companhia Nacional de Abastecimento (Conab) é de que sejam colhidas cerca de 128 milhões de toneladas de grãos na safra 2006/07, sendo que a soma das produções de soja e de milho deve representar cerca de $83 \%$ da produção nacional de grãos na safra em questão. Informação obtida em www.conab.gov.br, acesso em 25/maio/2007.
} 
parcerias, permite à Embrapa o cumprimento de suas funções públicas como uma das mais importantes IPPs nacionais. $\mathrm{O}$ que também exemplifica o cumprimento dessa função pública por parte da Embrapa é a implantação de uma política de negócios tecnológicos. Conforme Quental \& Gadelha (2000), a constatação de que a doação à sociedade dos resultados das atividades de $\mathrm{P} \& \mathrm{D}$ não estava garantindo uma distribuição justa dos benefícios gerados levou a uma maior preocupação com a valorização da tecnologia para ampliar sua transferência à sociedade. Ainda segundo os autores, a Embrapa busca agora identificar no mercado as demandas para fins de definição de prioridades de $\mathrm{P} \& \mathrm{D}$, assim como clientes ou parceiros interessados na difusão dos resultados, que a ajudem nessa tarefa.

Essa forma mais seletiva de transferência de tecnologia foi uma forma que a Embrapa encontrou para se articular na pesquisa e no mercado de sementes sem correr o risco de perder parte de seu principal porfólio, o seu banco de germoplasma. Conforme De Carli (2005), a Embrapa editou normas estabelecendo que os parceiros privados envolvidos em programas de melhoramento genético por ela conduzidos não podem possuir programas paralelo de pesquisa nessa área ou trabalhar em conjunto com organizações que tenham esses programas. "Tal exigência justifica-se pela preocupação da Embrapa em evitar mistura dos resultados dos programas de melhoramento, perda do controle $e$ qualidade das informações" (pg. 113). Ainda segundo o autor, outra preocupação é evitar que as empresas transnacionais de biotecnologia venham a controlar o germoplasma que se encontra sob seu domínio, por meio da aquisição de empresas nacionais de sementes que tenham acesso ao programa de melhoramento genético da Embrapa.

Isso aponta para uma questão importante: além da Embrapa executar suas atividades de P\&D de interesse público em mercados com diferentes graus de participação da iniciativa privada, a forma como o conhecimento gerado pela instituição (que pode estar materializado em novas cultivares, por exemplo) é transferido à sociedade também faz parte de uma estratégia de pesquisa que vise a ampliação dos benefícios econômicos e sociais decorrentes do novo conhecimento gerado. Ou seja, sobretudo nos mercados onde o grau de concorrência é maior, como nos mercados de soja, milho, por exemplo, as atividades de P\&D de interesse público estão diretamente relacionadas às atividades de transferência de tecnologia, o que destaca a necessidade de fortalecimento da política de propriedade intelectual da Instituição.

A execução das funções públicas das IPPs também passa por essa questão. Salles-Filho et al. (2000) ressaltam que tratar a questão da divulgação do conhecimento gerado nas IPPs apenas pelo princípio teórico de bens públicos e bens privados é insuficiente, exatamente pelo fato de assim não se considerarem as diversas formas de apropriabilidade e de rivalidade desenvolvidas no seio da economia capitalista, ainda mais complexa quando se fala da produção de conhecimento científico e tecnológico. Assim, se uma nova tecnologia é disponibilizada para certo segmento social com o fim de desenvolver a pequena produção e regular preços de mercados oligopolizados (medicamentos, sementes, por exemplo), "é preciso conhecer a dinâmica dos mercados, os mecanismos de apropriabilidade envolvidos e identificar e selecionar os agentes que podem tornar realidade aqueles objetivos maiores. Tornar público o conhecimento sem esses cuidados básicos é uma interpretação equivocada da função pública das IPPs" (pg. 84).

Entende-se que uma postura próativa das IPPs é fundamental nesse momento de maior concorrência com o setor privado. A Embrapa tem realizado uma reorganização institucional justamente para estar em condições de se 
manter atuante em importantes segmentos do mercado agrícola, inclusive com o desenvolvimento de produtos transgênicos. Dada a imensa importância dessa cultura para a agricultura nacional, entende-se que essas pesquisas são importantes, entre outras coisas, para evitar que esse segmento seja dominado pelas empresas multinacionais.

\section{O PAPEL DA PETROBRAS NA P\&D ATRELADA AO SETOR DE PETRÓLEO E GÁS NATURAL BRASILEIRO}

A Petrobras é uma sociedade de economia mista ${ }^{7}$ vinculada ao Ministério de Minas e Energia, criada pelo governo brasileiro em 1953 para diminuir as restrições à industrialização relativas a uma base pobre de recursos petrolíferos. $\mathrm{O}$ segmento petroleiro foi um dos pilares do modelo de industrialização por substituição de importações adotado pelo Brasil. Passadas cinco décadas de sua criação, a Petrobras, de acordo com o ranking criado pela Petroleum Intelligence Weekly, é a $14^{\mathrm{a}}$ empresa de petróleo do mundo, sustenta a liderança do segmento no Brasil e ocupa uma posição de destaque no contexto latinoamericano (Petrobras, 2005). A operadora nacional ostentou um lucro líquido recorde no ano de 2006: $\mathrm{R} \$ 25,9$ bilhões ( $9 \%$ superior ao ano anterior).

$\mathrm{O}$ esforço em P\&D, que sempre caracterizou as atividades da companhia, certamente é um dos motivos preponderantes para essa história de sucesso. O fato de ter criado em seu segundo ano de existência (1955) um órgão voltado à formação e ao desenvolvimento de recursos humanos, o Centro de Aperfeiçoamento e Pesquisa de

\footnotetext{
7 Segundo definição de Celso Antônio Bandeira de Mello (2002) "Sociedade de economia mista federal é a pessoa jurídica cuja criação é autorizada por lei, como um instrumento de ação do Estado, dotada de personalidade de Direito Privado, mas submetida a certas regras especiais decorrentes desta natureza auxiliar da atuação governamental, constituída sob a forma de sociedade anônima, cujas ações com direito a voto pertençam em sua maioria à União ou entidade de sua Administração indireta, sobre remanescente acionária de propriedade particular".
}

ENGEVISTA, v. 9, n. 2, p. 85-99, dezembro 2007
Petróleo (Cenap), embrião do atual Cenpes, corrobora a importância imputada pela empresa às atividades de P\&D. A partir da década de 1970, já rebatizado, o centro de $\mathrm{P} \& \mathrm{D}$ da Petrobras passa a se localizar na Universidade Federal do Rio de Janeiro (UFRJ), com vistas a incentivar e facilitar o intercâmbio com a comunidade científica da Universidade (Petrobras, 2007). Por apresentar um impacto muito negativo na balança comercial brasileira, a Petrobras foi induzida pelo setor público a buscar a auto-suficiência do país na produção de petróleo e a reduzir seu impacto nas importações de bens de capital. O papel do Cenpes foi fundamental, pois municiou a companhia nacional com soluções tecnológicas para reduzir os problemas oriundos de sua situação de importadora líquida (Ribeiro, 2005).

A Petrobras é a empresa que mais deposita patentes no Brasil, assim como, trata-se da companhia brasileira com o maior número de patentes depositadas no Estados Unidos. No Brasil, em 2005, à estatal foram concedidas 10 patentes e depositadas 80 solicitações. Fora do país, foram depositados 49 pedidos e obtidas 58 patentes. Essas informações evidenciam a importância atribuída pela Petrobras ao domínio de tecnologias atreladas às suas áreas de atuação, com destaque para a Exploração e Produção (E\&P) de petróleo e gás natural. Os esforços desenvolvidos pela operadora nacional na E\&P offshore a colocaram na fronteira tecnológica mundial. $\mathrm{Na}$ década de 1990, a competência tecnológica da Petrobras foi reconhecida no exterior: a empresa, por duas vezes, foi agraciada com o OTC Distinguished Achievement Award, prêmio máximo do setor de petróleo, por suas contribuições tecnológicas no que se refere à $\mathrm{E} \& \mathrm{P}$ em águas profundas (Petrobras, 2007).

Apesar de ser uma sociedade de economia mista, o que a imprime um perfil diferente da Embrapa, na medida em que sofre influência dos acionistas privados em suas atividades, o atendimento ao interesse público é algo marcante nos projetos levados a cabo 
pela Petrobras, desde sua criação. Dentre as ações da operadora nacional que apresentam um forte viés de política pública, pode-se destacar: o incentivo à criação e ao desenvolvimento de uma indústria para-petroleira ${ }^{8}$ no país; a geração de empregos diretos e indiretos; a realização de atividades de $P \& D$ que buscam assegurar o domínio de tecnologias estratégicas na produção nacional de petróleo, sobretudo aquelas relacionadas à produção em águas profundas e ultra-profundas, e minimizar o declínio dos campos maduros em terra e mar; a realização de atividades de P\&D que visam ao desenvolvimento de tecnologias para refinar o óleo brasileiro (mais pesado); a realização de $\mathrm{P} \& \mathrm{D}$ em energia renovável; a atuação direta e indireta em atividades de pesquisa e em cursos de pós-graduação relacionados à temática petróleo e gás natural etc.

$\mathrm{Na}$ década de 1990, o governo brasileiro promoveu a flexibilização do setor de petróleo e gás natural mediante a promulgação da Lei do Petróleo $\left(\mathrm{N}^{\circ}\right.$ 9.478/97), em 06/08/1997, a partir da qual toda empresa, nacional e estrangeira, pode realizar atividades de exploração, produção, transporte, refino, importação e exportação de petróleo no país, mediante autorização, permissão ou concessão da autoridade pública. Bonneli \& Veiga (2003, p. 11) afirmam que até a promulgação da Lei do Petróleo, que instituiu a quebra do monopólio da operadora nacional, "a Petrobras ocupava nos segmentos sob monopólio da União, o centro do triângulo cujos vértices são: política pública, regulação e operação". A partir da aprovação da Lei do Petróleo, criou-se o Conselho Nacional de Política Energética (CNPE) e a Agência Nacional de Petróleo (ANP), os quais passaram a ocupar os vértices da política pública e da regulação, respectivamente, restando à Petrobras a operação, na qual não ocupava mais a posição de monopolista.

\footnotetext{
${ }^{8}$ Neste trabalho os termos "indústria para-petroleira" e "parque supridor" são utilizados para designar o mesmo objeto, qual seja, o segmento industrial que fornece equipamentos e serviços à indústria do petróleo.
}

ENGEVISTA, v. 9, n. 2, p. 85-99, dezembro 2007
Portanto, a operadora nacional, a partir da instauração desse novo ambiente institucional no setor, perdeu a exclusividade e passou a ser legalmente obrigada a participar dos leilões promovidos pela $\mathrm{ANP}^{9}$, para obter áreas de exploração. Essa autarquia federal foi criada pela União com a atribuição de promover a regulação, a contratação e a fiscalização das atividades econômicas integrantes da indústria do petróleo (Ribeiro, 2005).

Sulisck, especialista no setor do petróleo brasileiro, afirma que a quebra do monopólio foi positiva para a Petrobras, porque antes se misturava uma empresa com um agente regulador (Com Ciência, 2002). Além disso, segundo o autor, observa-se uma série de indicadores acerca da atuação da companhia após o fím do monopólio, como o avanço nos investimentos em $\mathrm{P} \& \mathrm{D}$, na exploração e produção, faturamento etc., que confirmam o maior dinamismo da empresa nesse novo ambiente institucional. Em 2006, quase uma década após a quebra do monopólio, o Brasil alcançou a auto-suficiência na produção de petróleo, o que significa que passou da condição de importador líquido para exportador líquido de petróleo e derivados, reduzindo os gastos do país com divisas. Vale salientar a importância da Petrobras para que tal conquista fosse alcançada, porque, apesar de não ser a única produtora de petróleo no território brasileiro, é de longe a maior. Os esforços realizados pela empresa em $\mathrm{P} \& \mathrm{D}$, com destaque para o Programa Tecnológico de Águas Profundas (Procap), atualmente em sua terceira edição, formaram o alicerce tecnológico necessário para que o Brasil finalmente se tornasse auto-suficiente. A respeito

\footnotetext{
${ }^{9}$ A União Federal, não perdeu, segundo o artigo $3^{\circ}$ da Lei do Petróleo, a propriedade dos "depósitos de petróleo, gás natural e outros hidrocarbonetos fluidos existentes no território nacional, nele compreendidos a parte terrestre, o mar territorial, a plataforma continental e a zona econômica exclusiva". À ANP coube a função, após a quebra do monopólio da Petrobras, de realizar licitações para a concessão de áreas ou blocos destinados à exploração de petróleo e gás natural que, como já destacado, continuaram sendo propriedade da União (Brasil, 1997).
} 
dos projetos do Procap, Furtado \& Freitas (2004) destacam a importância da participação das universidades e das empresas fornecedoras nacionais e os impactos tecnológicos e de recursos humanos que a participação nesses projetos proporcionou a essas entidades.

Além disso, deve-se enfatizar o papel da cláusula de investimentos em P\&D que consta dos contratos de concessão para exploração, desenvolvimento e produção de petróleo e/ou gás natural, estabelecida entre a ANP e os concessionários, desde 1998. Conforme disposto no item $\mathrm{X}$ do artigo $8^{\circ}$ da Lei do Petróleo, é atribuição da ANP "estimular a pesquisa e a adoção de novas tecnologias na exploração, produção, transporte, refino $e$ processamento" (Brasil, 1997). Assim, para cumprir uma de suas atribuições previstas em lei, essa agência reguladora incluiu a cláusula de investimento em P\&D desde a Rodada Zero, em 1998. A característica central da cláusula ora tratada é a obrigatoriedade de que os concessionários realizem investimentos em P\&D ao percentual de, no mínimo, $1 \%$ da receita bruta proveniente dos campos para os quais haja incidência de Participação Especial ${ }^{10}$ (PE). Há também a exigência contratual de que pelo menos $50 \%$ desse total sejam utilizados na contratação de atividades de $\mathrm{P} \& \mathrm{D}$ em universidades e centros de P\&D brasileiros previamente credenciados pela ANP. A outra metade pode ser alocada nas instalações do próprio Concessionário, em suas afiliadas localizadas no Brasil ou nas empresas nacionais.

O valor acumulado entre 1998 e 2004 , referente a $1 \%$ da renda bruta dos campos para os quais a PE é devida, foi de R \$ 1,2 bilhão, em 2005 foi de R $\$ 508$ milhões e, finalmente, R\$ 707 milhões em 2006. De acordo com o diretor da ANP, Victor Martins, esses investimentos

\footnotetext{
${ }^{10}$ A cobrança da Participação Especial se aplica apenas aos campos com grande volume de produção ou de grande rentabilidade e varia entre $10 \%$ e $40 \%$ da receita líquida do campo, de acordo com a localização, produtividade e o tempo que está em operação (Brasil, 1998).

ENGEVISTA, v. 9, n. 2, p. 85-99, dezembro 2007
}

são utilizados para geração de conhecimento e para obter liderança tecnológica e cita os casos do etanol e dos biocombustíveis como áreas prioritárias. Ainda segundo Martins, a Petrobras vem investindo fortemente no Cenpes com recursos provenientes dos campos de alta produção (Oliveira, 2007).

Em 2005, a ANP flexibilizou a exigência de que os recursos fossem empregados apenas em atividades de $\mathrm{P} \& \mathrm{D}$, passando a admitir sua utilização em infra-estrutura laboratorial das universidades e centros de pesquisa envolvidos. Além disso, essa agência reguladora introduziu uma outra exceção, ao permitir que a Petrobras aplicasse dinheiro oriundo de sua quota-parte da cláusula, na formação de recursos humanos atrelada a projetos do Programa de Mobilização da Indústria do Petróleo e Gás natural (PROMINP). O Concessionário, por obrigação contratual, tem que fornecer à ANP um relatório completo das despesas qualificadas com P\&D realizadas, incluindo descrição dos aspectos técnicos e descrição auxiliar. De acordo com Aranha (2006), os resultados esperados pela ANP no que toca aos projetos de $P \& D$ financiados com recursos da $\mathrm{PE}$ são divididos em três categorias, a saber:

- Para o setor de petróleo e gás natural: contribuir para o suprimento das necessidades energéticas do país; aumentar e otimizar a produção nacional e; reduzir os custos de exploração, produção, transporte, refino e distribuição, com segurança e preservação do meio ambiente;

- Indústria nacional: promover o desenvolvimento tecnológico da indústria nacional - cadeia de fornecedores; aumentar a participação das empresas nacionais no setor e disponibilizar profissionais altamente qualificados;

- Instituições de P\&D: implantar centros de excelência para 
fomentar o desenvolvimento tecnológico do setor.

Ainda a respeito dos investimentos em $\mathrm{P} \& \mathrm{D}$ realizados no âmbito da indústria do petróleo do país pós-quebra do monopólio, não há como não destacar o papel desempenhado pelo fundo setorial CT-Petro. A criação do Plano Nacional de Ciência e Tecnologia do Setor Petróleo e Gás Natural - CTPetro - é praticamente simultânea ao início do processo de flexibilização do monopólio da Petrobras. Sua principal preocupação era impedir que houvesse um arrefecimento nas pesquisas científicas e no desenvolvimento tecnológico que levaram o Brasil a uma posição de destaque no cenário internacional em termos de tecnologias para exploração e produção de petróleo em águas profundas, alcançada préflexibilização (Martins, 2003). Os recursos que compõem o Fundo provêm dos royalties da produção de petróleo e gás natural no país ${ }^{11}$ e ele é gerido pela ANP e o MCT, este último representado pela Finep e pelo CNPq. As instituições habilitadas a demandar os recursos do CT-Petro são: as universidades e os centros de pesquisa brasileiros, públicos e privados. Apesar das empresas públicas e privadas serem estimuladas a participar dos projetos de $\mathrm{P} \& \mathrm{D}$ aprovados, tais instituições não podem submeter projetos sozinhas, devendo ser sempre intermediadas por uma universidade ou centro de pesquisa.

Concluindo, salta à vista a preocupação do governo brasileiro por meio do CT-Petro e da cláusula de participação especial de incorporar a lógica pública na $\mathrm{P} \& \mathrm{D}$ realizada pelo setor de petróleo, permitindo ao governo e à sociedade capturar parte da renda petrolífera. Além da $\mathrm{P} \& \mathrm{D}$ realizada deliberadamente pela Petrobras já possuir um desdobramento positivo para a sociedade brasileira, como, por exemplo, aquela relacionada à busca pela autosuficiência do país em petróleo, o

${ }^{11}$ O Fundo CT-Petro é formado por $25 \%$ da parcela do valor dos royalties que exceder a $5 \%$ da produção de petróleo e gás natural (Martins, 2003).

ENGEVISTA, v. 9, n. 2, p. 85-99, dezembro 2007 governo brasileiro, por meio da ANP e da Finep, tem buscado reforçar a P\&D de interesse público realizada diretamente pela Petrobras ou pelas universidades, centros de pesquisa e empresas brasileiras, por meio dos recursos oriundos da PE e dos Royalties.

\section{CONCLUSÕES}

O principal objetivo do artigo foi o de discutir a realização de $P \& D$ de interesse público por parte de importantes instituições brasileiras que desenvolvem pesquisas importantes em suas áreas de atuação. No caso da Embrapa, entende-se que a Instituição cumpre uma importante função tanto em mercados nos quais a iniciativa privada não tem interesse em investir, devido à menor rentabilidade, como também em mercados nos quais a presença do setor privado é significativa. Nos dois casos, as atividades de P\&D da Instituição são de interesse público. Mas, sobretudo nos mercados nos quais as empresas multinacionais estão adotando estratégias ofensivas - via aquisições de empresas nacionais, por exemplo - e/ou onde as pesquisas estão sendo afetadas pelos avanços na biotecnologia, a política de P\&D deve ser complementada pela política de transferência de tecnologia, o que passa necessariamente pela política de propriedade intelectual. Dessa forma, a política de propriedade intelectual se complementa à de $\mathrm{P} \& \mathrm{D}$ para a realização de atividades de interesse público sobretudo nos segmentos mais atrativos ao setor privado.

No caso da Petrobras, é evidente a importância dessa companhia desde sua criação dentro da indústria do petróleo e gás natural brasileira e uma de suas atividades de destaque é a P\&D. Por mais de quatro décadas a Petrobras deteve o monopólio da exploração, produção, pesquisa, lavra, refino e transporte do petróleo e derivados dentro do território brasileiro, reforçando seu papel no que diz respeito ao sistema setorial de inovação da indústria em questão. As restrições de divisas e a instabilidade cambial, somado ao fato da operadora 
nacional se tratar de uma importadora líquida, reforçaram a importância do Cenpes enquanto centro irradiador de novas tecnologias (sobretudo para refino e E\&P) adequadas às nossas especificidades. Como destacado ao longo deste trabalho, o governo brasileiro, com o objetivo de impedir que houvesse uma queda no dinamismo tecnológico do setor após a quebra do monopólio da Petrobras, criou a cláusula de investimento em P\&D e o CT-Petro, que agrega, além da operadora nacional, outros atores do sistema setorial de inovação da indústria do petróleo e gás natural brasileira.

Como não poderia deixar de ser, as práticas de $\mathrm{P} \& \mathrm{D}$ de interesse público variam de caso a caso. Isso revela que para o melhor entendimento de como se realiza o processo de pesquisa científica e tecnológica, um referencial conceitualteórico que considera uma divisão $a$ priori entre o que deve ficar a cargo do setor público ou do setor privado não é o mais adequado para o entendimento da dinâmica inovativa (se é que já foi um dia). O próprio conceito de P\&D de interesse público também é difícil de ser definido a priori, dado que diferentes segmentos possuem diferentes lógicas e diferentes espaços para a atuação dos setores público e privado. A forma de atuação das duas Instituições em análise é um exemplo a ser ainda melhor explorado, aprofundando a discussão de como Instituições Públicas são importantes para o desenvolvimento científico e tecnológico em áreas estratégicas, como é o caso das áreas-alvo das discussões aqui realizadas.

\section{BIBLIOGRAFIA}

Aranha, L.O.N. Investimento em P\&D para a indústria do petróleo e gás natural. IV SEMINÁRIO RIO-METROLOGIA, Rio de Janeiro, 20 de abril de 2006. Disponível em: < http://www.redetec.org.br/publique/medi a/rio_metrologia_2006_luiz_aranha.pdf $>$. Acesso em: 16 de abril de 2007.
Bandeira de Mello, C.A. Sociedades Mistas, Empresas Públicas e o Regime de Direito Público. Fórum Administrativo Direito Público, São Paulo, v. 01, n. 17, p. 871-875, 2002.

Blumstein, C.; Scheer, R.; Wiel, S. Public interest research and development in the electric and gas utility industries. Utilities Policy, v.7, n.4, pp.191-199, 1999.

Bonacelli, M.B., Salles-Filho, S.; Silveira, J.M., Gargalos tecnológicos e cadeias produtiva e inovativa da citricultura no Brasil. In: Dagnino, R. \& Thomas, H. Panorama dos estudos sobre ciência, tecnologia e sociedade na América Latina, Taubaté: Cabral Editora e Livraria Universitária, 2002.

Bonneli, R.; Veiga, P.M. A dinâmica das Políticas Setoriais no Brasil na década de 1990: Continuidade e Mudança. In: Revista Brasileira de Comércio Exterior, No 75 - Abril/Junho de 2003.

Brasil. Lei n. 9.478, de 06 de agosto de 1997. Dispõe sobre a política energética nacional, as atividades relativas ao monopólio do petróleo, institui o Conselho Nacional de Política Energética e a Agência Nacional do Petróleo e dá outras providências.

Brasil. Decreto n. 2.705, de 03 de agosto de 1998. Define critérios para cálculo e cobrança das participações governamentais de que trata a Lei n. 9.478, de 06 de agosto de 1997, aplicáveis às atividades de exploração, desenvolvimento e produção de petróleo e gás natural e dá outras providências.

Callon, M. Is Science a Public Good? Science, Technology \& Human Values, v.19, n.4, pp. 95-424, 1994.

Campanhola, C. Novos Significados e Desafios. Embrapa Informação Tecnológica, Brasília: 2004.

Com Ciência. Quebra do monopólio divide interesses empresariais e nacionalistas. Com Ciência, n. 38, dez. 2002. Disponível em: < http://www.comciencia.br/reportagens/fra mereport.htm $>$. Acesso em: 10 de abril de 2007. 
David, P.A.; Hall, B.H. Heart of darkness: modeling public-private funding interactions inside the $R \& D$ black box. Research Policy v.29, n.9, pp.1165-1183, 2000.

De Carli, C. R. Embrapa: precursora da parceria público-privada no Brasil, Brasília: Centro de Desenvolvimento Sustentável (CDS/UNB). Dissertação de Mestrado, 2005.

Fuck, M.P. Funções Públicas e arranjos institucionais: o papel da Embrapa na organização da pesquisa de soja e milho híbrido no Brasil, Campinas: Departamento de Política Científica e Tecnológica (DPCT/IG/Unicamp). Dissertação de Mestrado, 2005.

Furtado, A.T.; Freitas, A.G. Nacionalismo e aprendizagem no programa de águas profundas da Petrobras. Revista Brasileira de Inovação, v. 3, n. 1, pp. 55-86, jan./jun. de 2004.

Giambiagi, F.; Além, C. Finanças públicas: teoria e prática no Brasil. Rio de Janeiro: Ed. Campus, 1999.

Gomes, R. Pesquisa \& Desenvolvimento de Interesse Público e as Reformas no Setor Elétrico Brasileiro, Campinas: Faculdade de Engenharia Mecânica (FEM/Unicamp). Dissertação de Mestrado, 2003.

Mankiw, N.G. Introdução à economia: princípios de micro e macroeconomia, Rio de Janeiro: Editora Campus, 1999.

Martins, F.C. O Fundo CTPetro e o setor produtivo: análise de política científica e tecnológica para o desenvolvimento do fornecedor local de equipamentos $e$ serviços para o setor de petróleo e gás natural, Campinas: Departamento de Política Científica e Tecnológica (DPCT/IG/Unicamp). Dissertação de Mestrado, 2003.

Oliveira, N. ANP promove seminários para incentivar instituições de pesquisa e universidades a buscarem recursos do petróleo para investir em desenvolvimento tecnológico. Agência Brasil, Rio de Janeiro, 15 de março de 2007. Disponível em: < ENGEVISTA, v. 9, n. 2, p. 85-99, dezembro 2007 http://www.agenciabrasil.gov.br/noticias/ 2007/03/15/materia.2007-03-

15.3553185204/view>. Acesso em: $20 \mathrm{de}$ maio de 2007.

Petrobras. Relatório anual 2005. Disponível em: < http://www2.petrobras.com.br/ri/port/Con hecaPetrobras/RelatorioAnual/pdf/Relato rioAnual_2005.pdf>, Acesso em: $10 \mathrm{de}$ novembro de 2005.

Petrobras. Plano de negócios 2006-2010. Disponível em: < http://www2.petrobras.com.br/ri/port/Apr esentacoesEventos/ConfTelefonicas/pdf/ Plano_Negocios_2006-2010_n.pdf>, Acesso em: 10 de maior de 2007.

Quental, C.; Gadelha, C. Incorporação de demandas e gestão de P\&D em institutos de pesquisa. Revista de Administração Pública, Rio de Janeiro, 34 (1): 57-78, jan./mar. de 2000.

Ribeiro, C.G. A política de compras de entidades públicas como instrumento de capacitação tecnológica: o caso da Petrobras, Campinas: Departamento de Política Científica e Tecnológica (DPCT/IG/Unicamp). Dissertação de Mestrado, 2005.

Salles-Filho, S.; Kageyama, A. A reforma do IAC: um estudo de reorganização institucional. Revista de Administração Pública, v. 32, n. 3, pp.159-178, 1998.

Salles-Filho, S. (coord.) et al. Ciência, tecnologia e inovação - a reorganização da pesquisa pública no Brasil. Campinas: Editora Komedi, 2000.

Santos, A.M.R. O Fundo CTPetro: uma análise da $P \& D$ de interesse público para o setor petrolífero nacional. Campinas: Faculdade de Engenharia Mecânica (FEM/Unicamp), Dissertação de Mestrado, 2003. 